\title{
Factors influencing the genetic structure of Phacelia dubia, a species with a seed bank and large fluctuations in population size
}

\author{
RAFAEL F. DEL CASTILLO* \\ Department of Botany, Duke University and CIIDIR IPN Oaxaca, Mexico
}

\begin{abstract}
The potential factors that may influence the genetic structure of the gynodioecious annual Phacelia dubia were assessed using electrophoretic and ecological information at a locality in which the population size changed by about three orders of magnitude. Fluctuations in population size appeared to have little influence on the allelic composition, heterozygosity and mixed mating system of the population. Despite wide fluctuations in total population size, the estimated effective population size during $\left(N_{e}=20\right)$ and after the bottleneck $\left(N_{e}=28\right)$ was little changed. Also, a significant spatial substructuring, evidenced by a cline in MDH and by the $F$-statistics, was observed before and after the bottleneck. The recovery of the population and the preservation of genetic diversity was attributable in part to the seed bank in the soil. Spatial gene flow via seeds was small compared with pollen flow and both were restricted. Nevertheless, substructuring contributes to a small portion of the total inbreeding. Also, the rate of apparent selfing of male steriles did not provide evidence of biparental inbreeding. Most of the inbreeding, however, was within subpopulations and autogamy appears to be the major contributor. It was concluded that the mating system is the leading factor determining the genetic structure and that the seed bank ensures genetic constancy in time in the face of large fluctuations in population size.
\end{abstract}

Keywords: bottlenecks, breeding systems, effective population size, gene flow, gynodioecy, population structure.

\section{Introduction}

Population genetic structure has been considered a major determinant of the rate of evolution (Wright, 1932, 1977, 1988). Indeed, structured populations can evolve faster than panmictic populations as the former have gene flow as an additional source of favourable combinations of genes which might have originated in other local populations (see also Slatkin, 1987). Among the multiple factors that modify population genetic structure, the mating system, by being a genetic link between generations, can be the most important (Allard, 1975; Loveless \& Hamrick, 1984), but other factors may also be influential. Genetic drift is enhanced in small-sized populations or when dispersal is limited resulting in an overall increase in homozygosity (e.g. Turner et al., 1982; Lacy, 1987). If population size fluctuates widely, the influence of drift can be

*Correspondence: Hda. de Quiriceo 9, Bosque de Echegaray, Edo de Mexico 53310 , Mexico. intense as the generations with the smallest numbers have the most effect (Wright, 1969). On the other hand, factors such as the seed bank in the soil (Templeton \& Levin, 1979) and gene flow among populations (Slatkin, 1987) are expected to offset the effects of drift. Also, in partially inbred populations, mutational load and heterozygote advantage can increase the levels of heterozygosity of the populations even at neutral loci unlinked to those directly affecting fitness (Haldane, 1949; Ohta \& Cockerham, 1974; Hedrick, 1980; Charlesworth, 1991). Hence, understanding population genetic structure can be a useful tool to assess the action and interaction of various evolutionary forces in natural populations (Selander \& Whittman, 1983).

There is a considerable amount of information on the genetic structure of plant populations (e.g. Clegg \& Allard, 1972; Schaal \& Smith, 1980; Schwaegerle et al., 1986; Dewey \& Heywood, 1988; Soltis \& Soltis, 1988) and assessing the factors determining such structure is an active area of research. More studies are 
needed that integrate ecological and genetic information to provide a better picture of how genetic structure is shaped. For instance, fluctuations in population size are expected to be common in annual plants and in other species (Mac Arthur \& Wilson, 1967) but only a few studies have documented how the population structure changes during such fluctuations (Epling et al., 1960; Gottlieb, 1974). As many factors appear to act simultaneously in determining population genetic structure, it is necessary to consider as many potential factors as possible before we can draw conclusions about their relative importance.

This paper documents the spatial and temporal variation in population genetic structure in a gynodioecious annual plant over a 4-year period using electrophoretic markers. I also combine ecological and genetic information to explore the role of the different factors that might affect such structure. Specifically, I examine how the breeding system, population subdivision, gene flow and fluctuations in population size contribute to the levels of inbreeding and genetic variability of the population. The existence of male sterile individuals allowed estimations of biparental inbreeding and pollen flow. Of particular interest is the fact that during the study time the total population size fluctuated over several orders of magnitude. I also provide evidence of the importance of the seed bank in the soil in maintaining population size and genetic structure.

\section{Materials and methods}

\section{Study system}

Phacelia dubia (L.) Trel. (Hydrophyllaceae) is a winter annual distributed in the southeastern U.S.A. It grows in diverse habitats ranging from granite outcrops to forests (Putman, 1964; Murdy, 1966). Flowering at the study site takes place from mid-April to the first week in May. Most of the plants are hermaphroditic and selfcompatible (Levy, 1988; del Castillo, 1992, 1993) but male sterile plants, characterized by their lack of pollen production, have been observed in disturbed places near railroad embankments in south western Virginia (Levy, 1991; del Castillo, 1993). Male sterility appears to be controlled by nucleocytoplasmic factors (F. Levy, L. E. Broaddus, and R. F. del Castillo, unpublished data). The flowers are visited by syrphid flies and a variety of polylectic bees, including halictid bees which appear to be the major pollinators. Neither the seeds nor the fruits have any obvious adaptations for either wind or animal dispersal. The fruit is a capsule which discharges the seeds during and after the plants have senesced. Apparently, the desiccation of the fruit creates tension inside the fruit wall that forces out the seeds. Most of the seeds fall in the immediate neighbourhood of the parent, as indicated by observations of the trajectory of the seeds when discharged from the fruits and the distribution of seedlings in the field (R. F. del Castillo, personal observation). Seeds usually germinate in September and October; however, Spring germination has been observed occasionally (Murdy, 1966; R. F. del Castillo, personal observation). The seeds can remain dormant in the soil for several years (Baskin \& Baskin, 1973, 1978). In an early study of isozyme variation in this species carried out on 12 localities, Levy (1989) detected 38-60 per cent of polymorphic loci based on 14 enzymes assayed.

\section{Study site}

The study site is located in Montgomery County, approximately $1.5 \mathrm{~km}$ west of Radford Arsenal, VA. Here the individuals of $P$. dubia are distributed in patches (clusters of plants) along a strip of gravel and soil, approximately $860 \mathrm{~m}$ long and $0.5-4 \mathrm{~m}$ wide, situated between a railroad track and hardwoods. This set of patches was considered as the population for the purposes of this study. Other plants of the same species have been found along this railroad and in nearby woods but they are separated by at least $1.5 \mathrm{~km}$ from the study site. $P$. dubia occurs in association with Acer negundo, Actinomeris alternifolia, Cardus nutans, Cardamine hirsuta, Festuca obtusa, Specularia perfoliata and Veronica peregrina. This disturbed habitat, unusual for P. dubia (Levy, 1991), and the existence of male sterility without any detectable fitness advantage (del Castillo, 1993) suggest that the occurrence of this species is relatively recent at the study site.

\section{Population size, density and frequency of male sterility}

Figure 1 shows the positions of the patches for which distribution and number of individuals were monitored, during the flowering season, over 5 years. Each cohort established in the Fall, together with the occasional individuals that germinated in the Spring, is identified by the year of flowering. The population size was estimated from measurements of the length and width of each patch and from estimates of plant density within each patch based on 20-100 quadrats of 0.25 or $0.70 \mathrm{~m}^{2}$. At each quadrat, the numbers of male steriles and hermaphrodites were tallied. In 1989, all members of the population were mapped. The estimates of population size were based on flowering individuals, which essentially corresponded to the entire population, at the time of the tallies. 


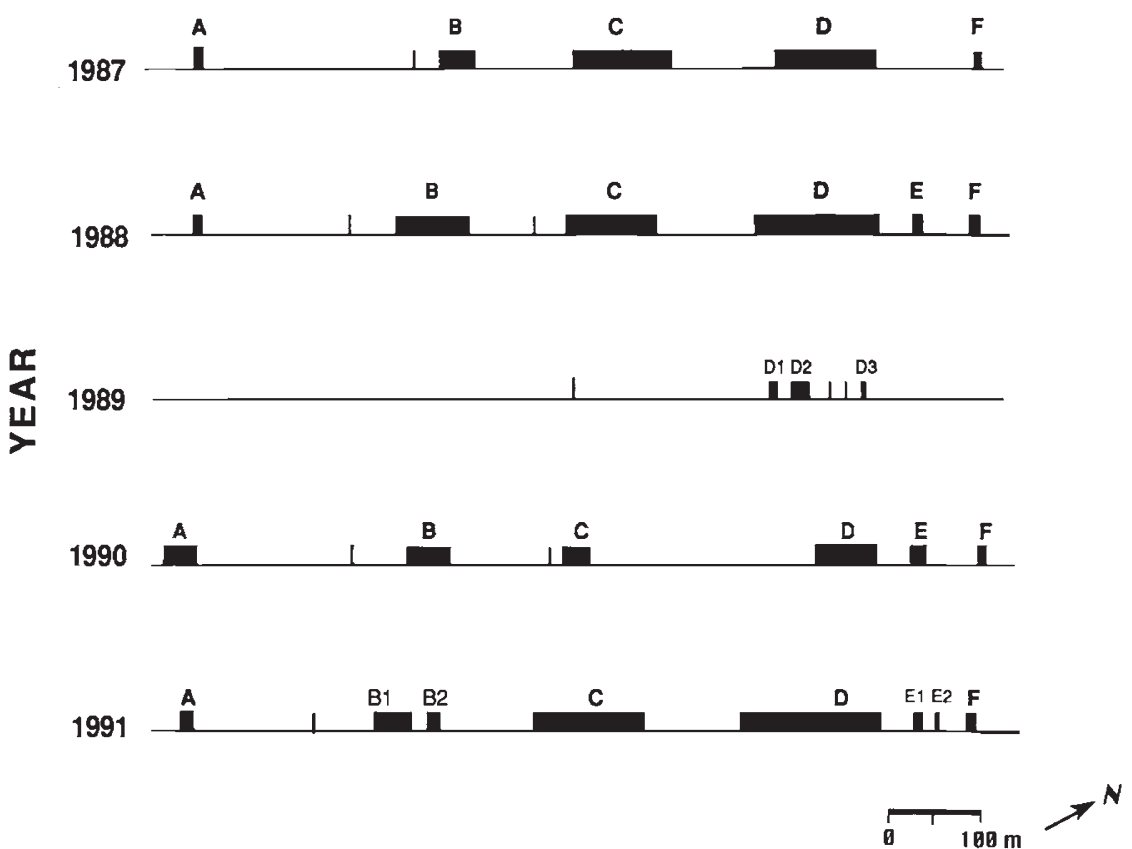

Fig. 1 Dynamics of patch distribution of Phacelia dubia near Radford, VA from 1987 to 1991 . The relative position of the patches at flowering time is indicated. The rectangles indicate presence of patches and vertical lines indicate the position of isolated individuals. Letters above the patches indicate the subdivision used in the $F$-statistics analysis. I did not sample plant material for electrophoretic analyses in 1987.

\section{Seed and pollen dispersal}

In 1988, I estimated pollen dispersal in the field by constructing an experimental population approximately $500 \mathrm{~m}$ from the study site but along the same railroad track. Ten hermaphrodite individuals, to be used as a pollen source, were collected at different positions from the study site and transplanted at the beginning of the flowering season into one quadrat $(50$ $\mathrm{cm} \times 50 \mathrm{~cm})$ at the experimental site. On one side of the hermaphroditic plants, pairs of male sterile individuals were planted at intervals of $0.4 \mathrm{~m}$ in a $12-\mathrm{m}$ linear array. As some male steriles did not survive the planting, one plant from each pair was removed, leaving only one plant per interval. All the flowers and fruits of the male sterile plants were detached leaving only flowering buds at the time of planting. The plants were left until the end of their life cycle and then collected. Effective pollen dispersal was estimated by the percentage of fruit set (fruit to flower ratio) determined on the male sterile plants as a function of the distance from the pollen source.

To estimate the seed dispersal curve, five individuals were collected from the field at the end of the fruiting season. These plants with mature fruits on them were positioned individually on an unobstructed surface so that their heights were the same as those in the field and the capsules were allowed to dehisce and discharge the seeds. I measured the dispersal distances of 240 seeds from the stem of the maternal plant to construct a frequency distribution of dispersal distances.

\section{Collection of material for electrophoresis}

In 1988, 1989 and 1990, seeds were obtained from 5 to 10 capsules per individual from 90,27 and 38 naturally occurring plants. After germination in a cold chamber, the seedlings were transplanted to plastic pots and placed in the greenhouse or growth chamber, as described in detail elsewhere (del Castillo, 1992). From each maternal plant, the leaves of randomly selected offspring in early rosette stage were used for electrophoresis. To compare the genetic structure at two different stages of the life cycle, I also analysed electrophoretically the 38 maternal plants of the 1990 seeds and a sample of 100 plants at flowering stage collected in the field in 1991.

\section{Electrophoresis}

Horizontal starch gel electrophoresis was performed on enzymes extracted from young leaf tissue. The enzymes were extracted as described in del Castillo (1992). The electrophoretic procedures, buffer recipes and staining protocols follow Soltis et al. (1983) and Levy (1989). The following four polymorphic enzymes were scored and interpreted: phosphoglucoisomerase-2 (PGI, E.C. 5.3.1.9), phosphoglucomutase (PGM, E.C. 2.7.5.1), isocitrate dehydrogenase-2 (IDH, E.C. 1.1.1.42) and malate dehydrogenase $(\mathrm{MDH}$, E.C. 1.1.1.37). PGI and PGM were assayed in a $\mathrm{LiOH}-$ borate $\mathrm{pH} 8.3$ gel buffer system at $40 \mathrm{~mA}$ and 80-100 V. IDH and MDH were assayed in a histidine- 
citrate $\mathrm{pH} 5.7$ buffer system at $30 \mathrm{~mA}$ and $150 \mathrm{~V}$ (maximum). Gels ran for $6-7 \mathrm{~h}$ at $4^{\circ} \mathrm{C}$. Genetic interpretation was based on segregation of progenies of naturally and artificially pollinated plants which suggested Mendelian inheritance (R. F. del Castillo, unpublished data; Levy, 1989 and personal communication). The loci were diallelic, except for PGI which was triallelic, with two common and one rare allele (slow, frequency 50.027 ). No evidence of linkage disequilibrium was detected in any of the pair-wise combinations of allozyme loci utilized (del Castillo, 1992).

\section{Analysis}

Population genetic structure was examined with loglinear models for categorical data analysis (Freeman, 1987 ) and Wright's $F$-statistics (see Wright, 1969). The former analysis was performed using genotypic frequencies as data entries and the procedure CATMOD of sAS (option ML, SAS Institute, 1987). The frequencies were pooled across years, excluding the juveniles of 1990 as they were derived from the sampled adults of that year and, therefore, did not provide independent information.

Spatial genetic structure was also analysed with Wright's $F$-statistics using the analysis of variance approach of Weir \& Cockerham (1984). In this analysis, $F$ is the overall inbreeding coefficient, i.e. the correlation of alleles within individuals in relationship to all populations (patches in this study), $\Theta$ measures the degree of differentiation between populations and $f$ measures the correlation of alleles within populations. These three parameters are related to Wright's $F$ statistics as $F=F_{I T}, \Theta=F_{S T}$ and $f=F_{I S}$ (Cockerham, 1969). Means of the estimates of these parameters were calculated by jackknifing over loci and 95 per cent confidence intervals were constructed from 1000 ordered bootstrap estimates, using loci as a resampling unit (Weir, 1990). This allowed a test of the null hypothesis that the value of the parameters is zero. The subdivision units were the patches observed in the population but in 1989, when the population numbers were small, the analysis was carried out at a level of subdivision (subpatches) that was at a smaller scale than that in the other seasons (Fig. 1). Patches labelled with the same letters corresponded to the same location across years and were pooled as a single patch for the pooled analyses. $F$-statistics analyses, where appropriate, were performed both for each season for juveniles (young rosette stage) and adults and by pooling the data available across years for each of the two stages of the life cycle studied. To avoid bias due to differences in offspring number sampled per plant, for the estimates of allelic frequency and for the $F$-statistics analyses one plant from each progeny was randomly chosen.

Single locus and multilocus estimates of outcrossing and their variances were obtained using the mixed mating model of Ritland \& Jain (1981). Outcrossing estimates during 1989 and 1990 were based on the progenies of 27 and 38 hermaphroditic plants, respectively, with an average of five and 10 offspring per family, respectively. In 1990, the genotypes of the parental plants were determined. Homogeneity of the single locus estimates of outcrossing for the 2 years studied was tested with a chi-square test developed for maximum likelihood estimates (Bailey, 1961).

Genotypic correlations in outcrossing matings can be an additional source of inbreeding and a factor that biases downwards outcrossing estimations based on the mixed mating model (Ennos \& Clegg, 1982; Ritland, 1984). One way to detect such genotypic correlations is to estimate the rate of apparent selfing in male sterile plants (Sun \& Ganders, 1988). An additional outcrossing estimation was made, therefore, in 1990 using all 11 male sterile plants that produced viable seeds in the study site in that season. An average of 12 individuals per maternal plant was used in this study. The genotypes of the male sterile maternal plants were also determined.

\section{Results}

\section{Fluctuations in population size and frequencies of male sterility}

During the study period, the total population size fluctuated over three orders of magnitude. Flowering plants were abundant in 1987 and 1988 but this was followed by a population crash in 1989. A partial recovery in population size was observed in 1990 and a full recovery in 1991, with an estimated population size of the same order of magnitude as in 1987 and 1988 (Fig. 2). The plants were distributed in a series of patches of relatively constant position throughout all the studied seasons (Fig. 1). The exception was the plants of 1989 which were distributed in small patches in what corresponded to patch $\mathrm{D}$ in the other years. The low population size in 1989 was probably due to a severe drought in 1988 (Trenberth et al., 1988). The proportion of male sterile plants also changed considerably, being close to 10 per cent in 1988 and in 1989 , less than 1 per cent in 1990 and close to 5 per cent in 1991 (Fig. 3). 


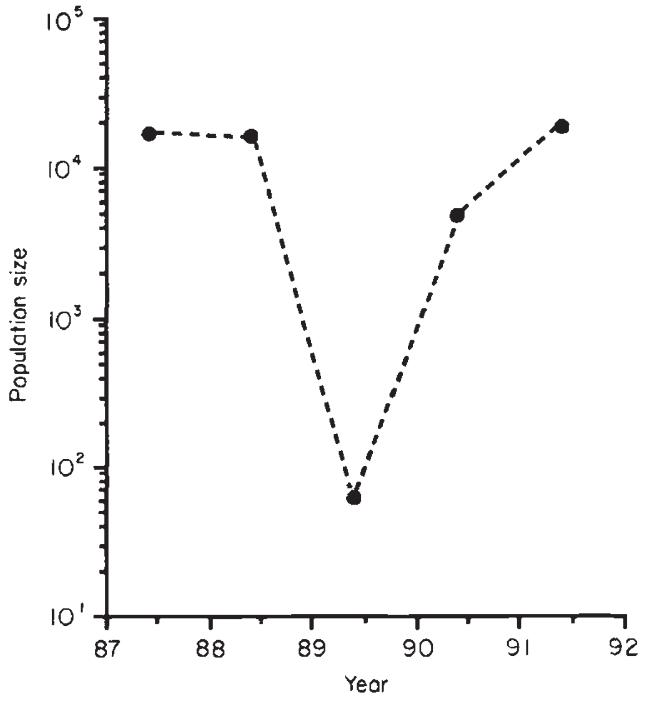

Fig. 2 Changes in population size from 1987 to 1991 (estimated number of flowering plants, see text).

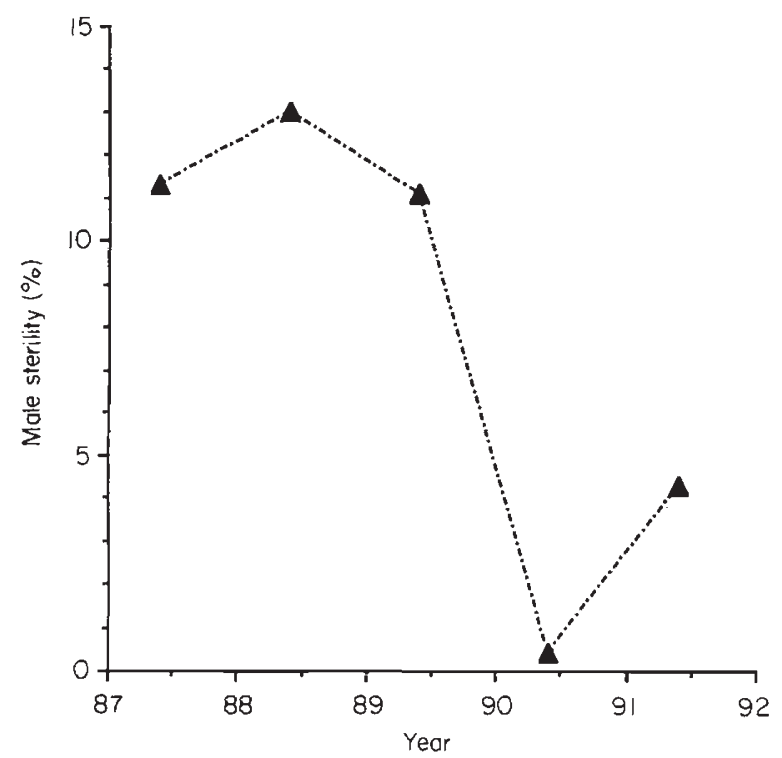

Fig. 3 Frequency of male sterile plants from 1987 to 1991.

\section{Pollen and seed dispersal}

The shapes of the curves of pollen and seed dispersal did not differ significantly from that of a normal distribution $(P>0.4$, Shapiro-Wilk Statistics, Conover, 1980). Fruit set declined as the number of individuals between the pollen source and the recipient plant increased and plants separated by more than eight individuals from the pollen source did not set fruit (Fig. 4). The standard deviation of pollen dispersal in the experimental population was $1.3 \mathrm{~m}$ or 3.4 individuals from the source plant in a given direction. The latter quantity is more informative as pollinators usually tend

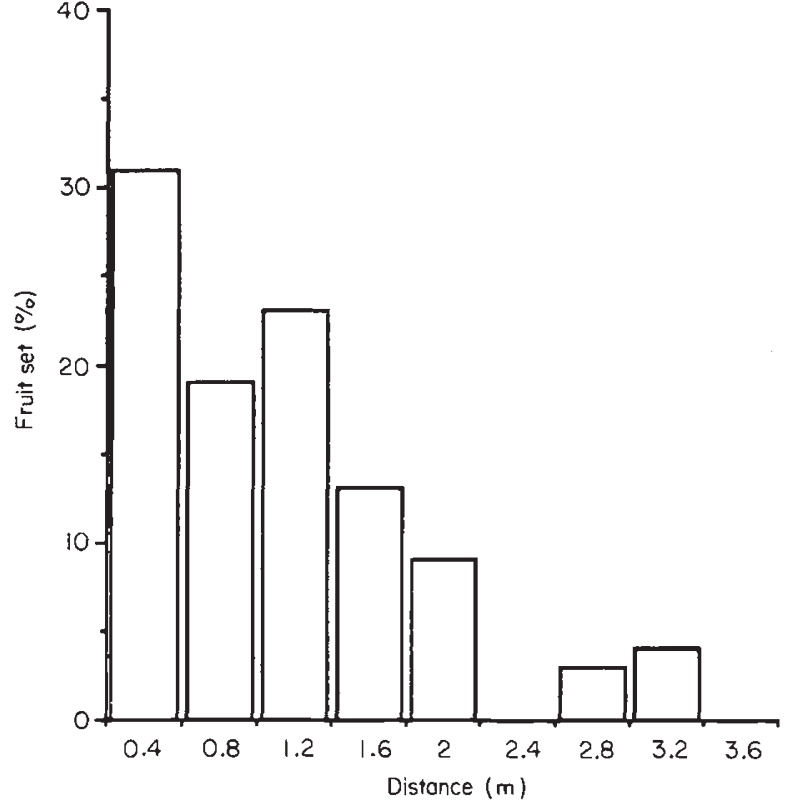

Fig. 4 Relationship between pollen dispersal, expressed as fruit set on male sterile plants, and distance from the pollen source.

to forage shorter distances when plants are dense (Levin \& Kerster, 1974; Handel, 1983a; Fenster, 1991). This appears to be the case for $P$. dubia at the study site as no other major alternative floral resources were available for pollinators during its flowering period. Seed dispersal was even more restricted: 94 per cent of the seeds were dispersed within the first $0.4 \mathrm{~m}$ from the maternal plant and no seeds were detected beyond $0.8 \mathrm{~m}$ (Fig. 5). The standard deviation of seed dispersal was $0.2 \mathrm{~m}$.

\section{Allelic frequencies}

Despite the changes in population size, polymorphism at all isozyme loci monitored was maintained during all years in the juveniles and adults analysed. Indeed, for $P G l, M D H$ and $I D H$ the allelic frequencies were remarkably constant over time (Figs. 6 and 7). $P G M-f$ showed a trend towards reduction in frequency with time (Fig. 6) but the population bottleneck of 1989 had no visible effect.

\section{Spatial subdivision and F-statistics}

The frequency of the fast allele of $M D H$ increased from south to north (Fig. 8). This trend was consistent across seasons and was also evident in the log-linear analysis after the Bonferroni correction for experiment-wise error considering that four enzymes were analysed (Weir, 1990; $\chi_{[2]}^{2}=15.35$, adjusted $P<0.003$ ). 


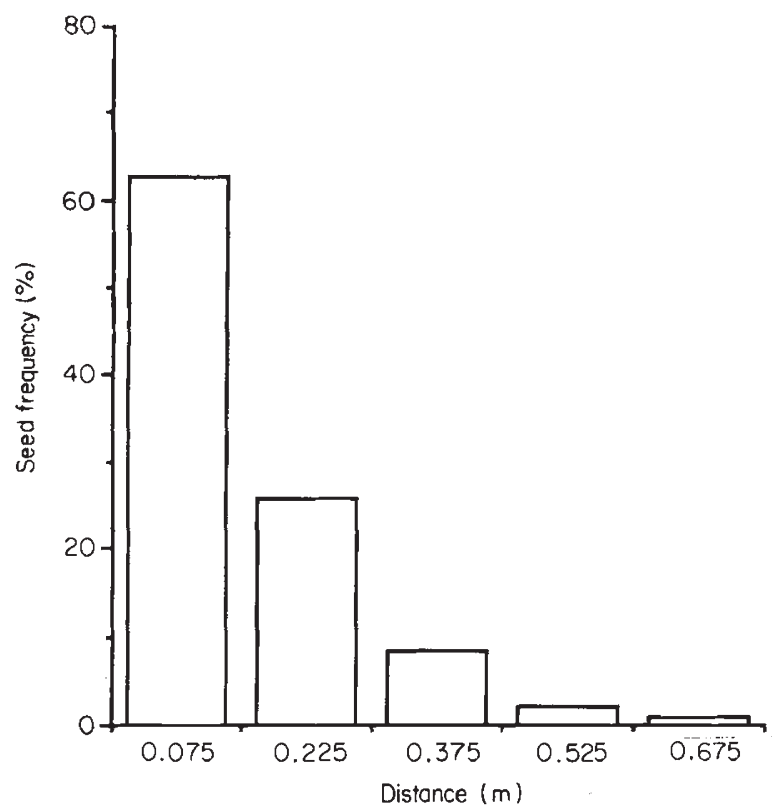

Fig. 5 Distribution of seed dispersal distances from the maternal plant.
$\triangle P G /-f$
口 $P G M-f$
- $P G I-s$

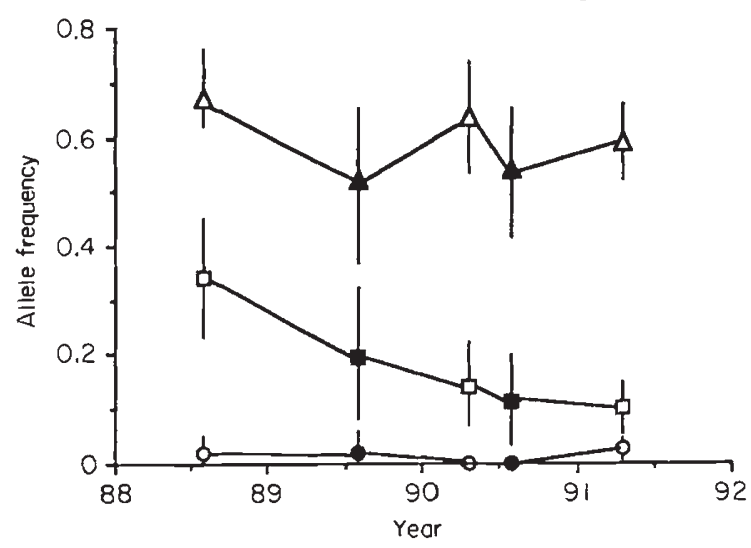

Fig. 6 Allelic frequencies and 95 per cent confidence intervals from 1988 to 1991 of $P G I$ fast and slow and $P G M$ fast. The confidence intervals were constructed by bootstrapping over individuals. Open figures represent seed samples taken from plants collected in the field. Solid figures represent samples of field flowering individuals.

No relationship between the spatial arrangement of the patches and genotypic frequencies was detected for any of the other loci studied (analyses not shown).

The combined estimates over all the alleles sampled of $F$, the total inbreeding coefficient, revealed heterozygote deficiency in all seasons and ontogenetic states (Table 1). This deficiency tended on average to be higher in juveniles than in adult plants. The primary

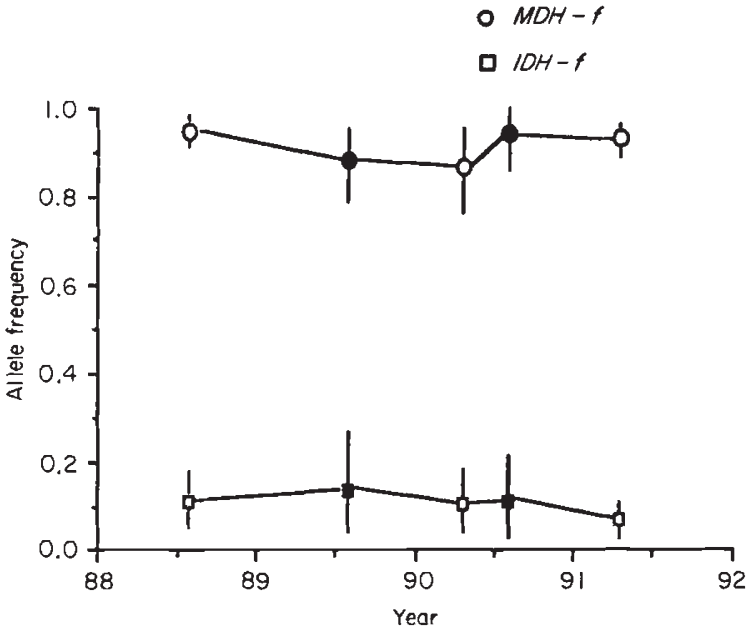

Fig. 7 Allelic frequencies of $I D H$ fast and $M D H$ fast and 95 per cent confidence intervals from 1988 to 1991 . Symbols and confidence intervals as in Fig. 6.

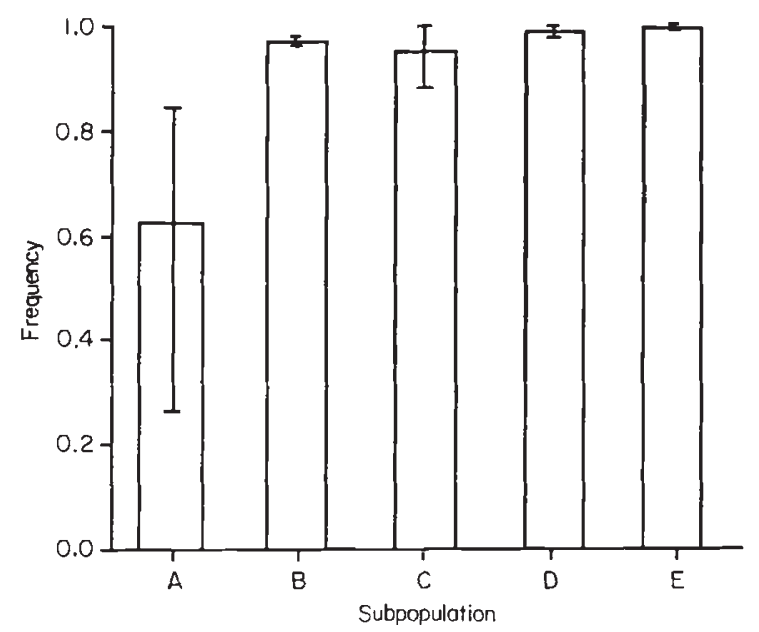

Fig. 8 Means of frequencies of the fast allele of $M D H$ in each of the subpopulations (patches). Letters correspond to the subpopulations as shown in Fig. 1. Subpopulations with common letters were pooled. Vertical bars are bootstrapped 95 per cent intervals of sampling periods (= ranges).

component of $F$ was at the level of individuals within patches and was significantly different from zero in all the cases studied. Also, there was a smaller component of $F$ due to population subdivision at the level of patches as seen in the pooled analysis on the juveniles and in the analyses on the adults.

The relative strengths of drift in population substructure can be assessed by the estimation of $N_{e} m$, where $N_{e}$ is the effective size of the population and $m$ is the migration rate (Wright, 1932). In an $n$-island model, for neutral alleles, and provided that $m$ is small, $\Theta$ approaches the formula: 
$\Theta=\left(4 N_{e} m \alpha+1\right)^{-1}$,

where $\alpha=[n /(n+1)]^{2}$ (Crow \& Aoki, 1984). Values of $N_{e} m>1$ indicate that gene flow is enough to prevent substantial differentiation among subpopulations caused by drift. At the level of patches and using juvenile plants, the $F$-statistics analysis for 1990 gives an estimate of $N_{e} m$ of 1.2. Given the short dispersal distances and the linear arrangement of the patches, it is likely that migration occurs mostly between adjacent subdivisions. The studied populations are more similar to a stepping stone structure. In this case, eqn 1 underestimates the actual value of $N_{e} m$.

Table $1 F$ statistics of Phacelia dubia near Radford, VA. Means were jackknifed over loci and significance tests were based on 95 per cent confidence intervals estimated by bootstrapping over loci. The juveniles were derived from seeds collected in the year indicated

\begin{tabular}{llll}
\hline Year & \multicolumn{1}{c}{$F$} & \multicolumn{1}{c}{$\Theta$} & $f$ \\
\hline Juveniles & & & \\
1988 & $0.270^{*}$ & 0.023 & $0.244^{*}$ \\
1989 & $0.172^{*}$ & $0.008^{\dagger}$ & $0.162^{*}$ \\
$\quad 1990$ & $0.220^{*}$ & 0.127 & $0.111^{*}$ \\
$\quad$ Pooled & $0.207^{*}$ & $0.049^{*}$ & $0.167^{*}$ \\
Flowering adults & & & \\
1990 & $0.223^{*}$ & $0.127^{*}$ & $0.103^{*}$ \\
1991 & $0.053^{*}$ & $0.026^{*}$ & $0.026^{*}$ \\
Pooled & $0.110^{*}$ & $0.023^{*}$ & $0.087^{*}$ \\
\hline
\end{tabular}

*Estimates significantly different from zero at 5 per cent. $\dagger$ Population subdivision in this season was at a lower spatial scale (subpatches) than in the other seasons (see Fig. 1).

Table 2 Outcrossing rate estimates and standard errors of Phacelia dubia hermaphrodites near Radford, VA, for 2 years based on the Ritland \& Jain (1981) mixed mating model

\begin{tabular}{lccccc}
\hline & \multicolumn{4}{c}{ Year } \\
\cline { 2 - 3 } \cline { 5 - 6 } & \multicolumn{2}{c}{1989} & & \multicolumn{2}{c}{1990} \\
\cline { 2 - 3 } \cline { 5 - 6 } Locus & $T$ & (S.E.) & & $T$ & (S.E.) \\
\hline$P G l-2$ & 0.654 & $(0.129)^{*}$ & & 0.867 & $(0.071)$ \\
$P G M-1$ & 0.644 & $(0.194)$ & & 0.629 & $(0.102)^{*}$ \\
$I D H-2$ & 0.554 & $(0.175)^{*}$ & & 0.669 & $(0.112)^{*}$ \\
$M D H-1$ & 0.631 & $(0.188)^{*}$ & & 0.501 & $(0.127)^{*}$ \\
Mean $\dagger$ & 0.626 & $(0.082)^{*}$ & 0.726 & $(0.048)^{*}$ \\
Multilocus & 0.672 & $(0.081)^{*}$ & 0.683 & $(0.043)^{*}$ \\
\hline
\end{tabular}

$\lceil$ Minimum variance mean.

*Rejection of the null hypothesis that $T=1$ at 5 per cent.

\section{Breeding systems}

During the two seasons where this was possible, the multilocus estimations of outcrossing indicated that $P$. dubia hermaphrodites have a mixed-mating system; the estimates differed significantly from random mating and from complete selfing (Table 2). The multilocus estimate of 1989, when the population size was small, was lower than that of 1990 , both for the cohort as a whole as well as for patch $\mathrm{D}(T=0.824 \pm 0.069$ mean and S.E.) but in neither case was the difference significant $\left(\chi_{[1]}^{2}=0.01\right.$ and $\left.\chi_{[1]}^{2}=2.01\right)$. Violation of the mixed-mating model assumptions can generate significant differences between the mean outcrossing rates of single locus estimates and the multilocus estimates (Ritland \& Jain, 1981; Shaw et al., 1981). As the single locus estimates are estimates of a single parameter, these estimates were combined by weighting their values by their variances (Mather, 1946). These minimum variance means were not significantly different from the multilocus estimates (Table 2). Also, heterogeneities among single locus estimates indicate departures from the mixed-mating model due to effects such as selection or mating among relatives (Clegg, 1980; Ritland \& Jain, 1981; Shaw et al., 1981). No heterogeneity among single locus estimates was detected in $1989\left(\chi_{[3]}^{2}=0.15\right.$, n.s. $)$ but in 1990 , the estimates were significantly heterogeneous $\left(\chi_{|3|}^{2}=9.17, P=0.028\right)$.

The fitness differential between self and outcross progenies biases the outcrossing estimates (see for example Snyder et al., 1985). In P. dubia, the fitness of the self progeny relative to that of the outcross progeny, from seed to juvenile stages $(w s)$, is 0.86 under the same conditions as those in which the progenies for outcrossing estimates were grown (36 families analysed, R. F. del Castillo, unpublished data). The multilocus estimates weighted by this value were 0.578 in 1989 and 0.587 in 1990 .

For the multilocus estimate of the outcrossing rate of male steriles, $M D H$ was excluded from the analysis owing to the low frequency of the slow allele in the progenies of these plants $(0.04)$. The multilocus estimate was $1.278 \pm 0.070$ (mean and S.E.), confirming that male sterile plants are outbred. This analysis, therefore, does not provide evidence of biparental inbreeding in $P$. dubia.

A population estimate of the outcrossing rate can be obtained by weighting the outcrossing estimates of hermaphrodites (multilocus estimate weighted by ws) and male steriles $(T=1)$ by the frequency of each sex morph. Thus, the population estimates of outcrossing were 0.625 and 0.589 in 1989 and 1990 , respectively. 


\section{Effective population size}

The degree to which genetic drift can change the rates of allelic fixation depends on the effective size of the population $N_{e}$. This value depends on two quantities: (i) the number of breeding individuals per unit area $(\delta)$ and (ii) the dispersal rate $(\sigma)$. Assuming a random mating population with stationary gene flow, i.e. no net movement of gametes (Levin \& Kerster, 1974), Wright (1946) found a method of relating $N_{e}$ to $\delta$ and $\sigma$. For gynodioecious populations, like those of $P$. dubia, in which (i) the dispersal rates of seeds (diploid, $\sigma_{o}$ ) and pollen (haploid $\sigma_{p} / 2$, Levin \& Kerster, 1974) are different and normally distributed, (ii) a fraction $(1-m s)$ of the breeding plants produces pollen and (iii) part of the progeny is the product of selfing, $N_{e}$ can be estimated as:

$2 \pi(1-m s) \delta r\left(\sigma_{o}^{2}+\sigma_{p}^{2} / 2\right)$

where $r$ is the proportion of random mating. The estimated density in 1989 was 0.523 plants $/ \mathrm{m}^{2}$ whereas that in 1990 was 48.3 plants $/ \mathrm{m}^{2}$. If $N_{e}$ is relatively large, $r$ can be equated to the total outcrossing rate of the population. If pollinators adjust their flight distances as a function of plant density (Levin \& Kerster, 1974; Handel, 1983a; Fenster, 1991), the standard deviation of pollen dispersal in metres $\left(\sigma_{p}\right)$ can be approximated as: $\sigma_{i} \delta^{-1 / 2}$, where $\sigma_{i}$ is the standard deviation of pollen dispersal of the experimental population expressed as the number of individuals from the source plant in a given direction. The estimates of $N_{e}$ were $20\left(\sigma_{p}=4.6 \mathrm{~m}\right)$ in 1989 , and $28\left(\sigma_{p}=0.48 \mathrm{~m}\right)$ in 1990 . Using the latter estimate and eqn 1 , migration rate among patches $(m)$ was estimated as 0.04 .

\section{Discussion}

\section{Fluctuations in population size}

The decrease in total population size to less than 100 plants in 1989 suggests a potential opportunity for genetic drift; therefore, a loss of genic variation, including a reduction in the number of alleles per locus, is expected (Nei et al., 1975). The individuals present during the bottleneck were distributed in a single patch; consequently, given the low seed dispersal rates, they all were likely to be derived from plants of the same patch. Thus, they are expected to be more related among themselves than a random sample of individuals derived from all the patches of the previous year. This creates an additional component of drift (Slatkin, 1977) which suggests even greater chances of genetic loss. There was, however, no loss of alleles after the bottleneck for all the enzymes assayed. PGI-s, a rare allele, could not be detected in the sampled adults of 1990 but was detected in their seeds and in the adult samples of the following year.

The decrease in frequency of male steriles in 1990 could have been attributed to the bottleneck effect. In $P$. dubia, the genetic determination of sex appears to be controlled by cytoplasmic factors causing male sterility and by nuclear genes (restorers) that re-establish male fertility on a particular cytotype (F. Levy, L. E. Broaddus and R. F. del Castillo, unpublished data). Therefore, chance over-representation of particular cytotypes and particular nuclear restorers provides an explanation for the observed shift in the frequency of male sterile plants from 1989 to 1990 (Fig. 3). Nevertheless, oscillations in the dynamics of male sterility in gynodioecious species can be reproduced in numerical models in systems controlled by nucleocytoplasmic factors, as is the case of $P$. dubia, without including bottleneck effects (Gouyon et al., 1991; del Castillo, unpublished data).

In the absence of other forces, the bottleneck effect at generation $t$ in a species with a mixed mating system is expected to increase the $F$ value at generation $t+1$ to:

$F_{t+1}=\frac{1}{2}\left(1+F_{t}\right) S+(1-S) G_{t}$,

where $S=1-T$ is the selfing rate of the population and $G_{t}$ is the coancestry coefficient at time $t$ (after Crow \& Kimura, 1970). Selfing rates include a component of selfing due to random mating in a finite population. This component is inversely proportional to $2 N_{e}$, where $N_{e}$ is the effective population size (see Crow \& Kimura, 1970). As $N_{e}$ approaches zero, selfing rates are expected to change widely with small changes in $N_{e}$ but the opposite is true as $N_{e}$ increases above 15-20. Thus, the slight and non-significant differences observed in the estimates of $S$ and $F$ in 1989 and 1990 and the estimates of $N_{e}$ suggest that the decrease in $N_{e}$ was not as dramatic as the decrease in total population size in 1989. Moreover, the low and non-significant value of $\Theta$ suggests that the population was panmictic or nearly so in 1989 .

Past bottlenecks appear to reduce electrophoretic variation in natural populations of some species of plants (Fowler \& Morris, 1977; Lesica et al., 1988). In other species, however, founder events decrease only slightly allelic polymorphism and have a minimal effect on heterozygosity (Taggart et al., 1990; Betancourt et al., 1991). Also, previous studies on bottlenecks have failed to detect any effect in populations of $P$. dubia occurring along railroad tracks in Virginia (Levy, 1989). Thus, reductions in population size do not necessarily lead to a genetic depauperation pre- 
sumably because other factors in the biology of the species act to preserve genetic variation.

\section{Seed bank in the soil}

In $P$. dubia, the seed bank may play a major role in ameliorating the genetic consequences of the bottleneck and in recovering the population following the bottleneck. In the field, seeds stored in the soil for 1 year showed an average of 10 per cent of germination when the soil was watered ( 5.0 per cent, selfed seeds; 12.6 per cent, outcrossed seeds, R. F. del Castillo, unpublished data). Considering the average seed production per plant in the field $(250$ seeds, del Castillo, 1992, 1993) and the population size the year before the bottleneck (1988, Fig. 2), at least 400,000 viable seeds from the 1988 cohort were present in the soil in the fall of 1989. Therefore, an insufficient number of safe sites rather than an insufficient number of viable seeds may explain the low rates of establishment even in good years. In the study site, the seed pool is almost certainly responsible for the consistency of patch distribution through seasons. It is unlikely that the recovery of patches $\mathrm{A}, \mathrm{B}, \mathrm{C}, \mathrm{E}$ and $\mathrm{F}$ following their disappearance in 1989 can be explained by colonization from seeds derived from patch $\mathrm{D}$, given the limited seed dispersal distances observed in this species (Figs 1 and 5).

The seed bank can function as an "evolutionary memory' which stores genotypes for a variable number of years; this memory is selective because it favours those years with large seed crops (Templeton \& Levin, 1979). The seed bank, therefore, can help explain not only the preservation of population size after the bottleneck but also the persistence of the genetic diversity and the MDH cline in P. dubia. The seed bank has seldom been considered in studies of population structure; however, the constancy in gene frequency detected in other annuals with large fluctuations of population size has been attributed to the seed bank (Epling et al., 1960; Gottlieb, 1974).

The seed population in the soil has a similar effect in time as dispersal does in space. With seed banks, each generation can be considered to result, in part at least, from the transfer of genes from several populations in the past and there is, therefore, an additional source of gene flow. Thus, the seed pool in the soil from favourable years is the temporal equivalent of Pulliam's (1988) source habitats. Although gene flow has been considered a homogenizing agent reducing the genetic variation among populations (Wright, 1969; Slatkin, 1987), in this case gene flow due to the seed bank preserves the spatial genetic structure. Thus, temporal and spatial sources of gene flow can have quite opposite effects in populations.

\section{Pollen and seed dispersal}

The dispersal results show that spatial gene flow is rather restricted. This is consistent with the patterns of seed dispersal of species with capsules (Levin \& Kerster, 1968; Augspurger, 1980; Cook, 1980; Schaal, 1980; Lee, 1984; Fenster, 1991) and with the dispersal rates of pollen of entomophilous plants (Levin \& Kerster, 1968; Augspurger, 1980; Schaal, 1980; Handel, 1983b). Nevertheless, in P. dubia, pollen appears to be dispersed at much longer distances than seeds, particularly at low densities as those of 1989 . This difference in dispersal is expected to generate a slight excess of heterozygotes (Prout, 1981) and may, therefore, help to prevent a great loss in heterozygosity during bottleneck events.

The rates of seed and pollen dispersal are crude estimates of the actual gene flow. If outcrossing distances affect fitness, then the estimates of gene flow should weight such an effect (Levin, 1981). Outcrossing distances, however, did not have a significant effect on seed viability and seed production in $P$. dubia $(n=85$, $r^{2} \leq 0.11$, n.s., linear and quadratic effects tested; R. F. del Castillo, unpublished data).

The method used here for the estimation of pollen flow probably avoids some of the problems of other methods involving following pollinators or assessing deposition of pollen or pollen analogues on stigmas, as it is based on fruit set which includes not only dispersal but also successful mating. Nevertheless, male sterility may itself affect pollination because the flowers of male sterile plants are smaller in diameter than those of hermaphrodites $(0.61 \pm 0.02$ vs. $0.95 \pm 0.02 \mathrm{~mm}$, mean and S.E.) and do not produce pollen. Differences in floral characters determining advertisement and rewards to pollinators affect pollen flow in other species (Waddington, 1983; Waser, 1983; Murcia, 1990; Young \& Stanton, 1990). In particular, the average number of flowers reached by donor pollen may be higher in emasculated flowers than in pollencarrying flowers (Price \& Waser, 1982). Thus, male steriles may favour longer pollination flights and, therefore, actual pollen flow might be overestimated with these plants.

Secondary seed dispersal (Phase II of dispersal, Watkinson, 1978) is unlikely to be important in $P$. dubia because: (i) the seeds lack aerodynamic features that favour wind dispersal (see Burrows, 1986); (ii) even under high winds no seed movement was detected in the soil (R. F. del Castillo, personal observation) and (iii) small seed size, as that of $P$. dubia (0.8 mm length), increases the probability of the seed being trapped in soil (Chambers et al., 1991). Nevertheless, seed dispersal is not only affected by the physical properties of the plants and seeds but also by the habitat. Compared 
with dense areas, open habitats tend to favour higher dispersal rates (Watkinson, 1978; Lee, 1984; Fenster, 1991). Thus, seeds from individuals in low density stands, as in 1989, are likely to be dispersed further than those in dense stands, as in 1990 . This could be an additional factor that minimizes the differences in $N_{e}$ between the 2 years.

\section{Spatial structure}

The coefficient $\Theta$ and the MDH cline indicate spatial structuring of genetic variation. Additional evidence of substructuring is provided by the existence of heterogeneity in the germination rates among patches (del Castillo, 1992). Moreover, the heterogeneity detected among the single locus estimates of outcrossing in 1990 may also indicate some assortative mating due to population subdivision (see Clegg, 1980; Shaw et al., 1981). In contrast, the homogeneity of the single locus estimates in 1989 may reflect the lack of structuring in that year when the population was restricted to one patch. Thus, the low $M D H$ outcrossing estimate in 1990 is probably due to the spatial cline in this locus, as spatial structure biases outcrossing estimates downwards (Ennos \& Clegg, 1982; Ellstrand \& Foster, 1983; Fu et al., 1992). Indeed, when $M D H$ was removed, no heterogeneity among single locus estimates was detected in $1990\left(\chi_{[2]}^{2}=4.57, P>0.1\right)$; however, the increase in value of the multilocus estimate was not significant $\left(T=0.771 \pm 0.047, \chi_{[1]}^{2}=1.91\right.$, $P>0.1)$. These results, therefore, provide support for the common finding that natural populations are genetically spatially structured (Wright, 1978; Brown, 1979; Loveless \& Hamrick, 1987; Cugen et al., 1988, etc.). In $P$. dubia, the genetic substructuring can be explained in part by very localized seed and pollen dispersal and in part by the large gaps between patches which may serve as barriers to gene flow. Simulation studies have shown that limited gene flow results in high levels of inbreeding, population subdivision and increased homozygosity (Turner et al., 1982). Also, the distribution of the population in a linear arrangement is expected to amplify the effects of population subdivision (Kimura \& Weiss, 1964; Wright, 1969; but see Slatkin, 1985).

Despite the limited rates of pollen and seed dispersal, genetic subdivision accounted for only a small portion of the total inbreeding detected. This appears to be common in other plant species (Heywood, 1991) including plants with limited gene flow (e.g. Schaal, 1975). In P. dubia, the lack of genetic equilibrium due to the frequent disturbances to which the study site is likely to be exposed may explain this result. Alternatively, the small migration detected between patches may play an important role in overcoming the effects of drift due to population subdivisions, as has been shown theoretically (see Lacy, 1987).

\section{Breeding systems}

Most of the inbreeding detected here was at the level of individuals within subpopulations, probably as a result of autogamy. Indeed, the outcrossing estimate in male sterile plants did not provide evidence of biparental inbreeding or other types of assortative mating. Selfing can result from direct action of pollinators as protandry is not absolute and seed production can result from flowers self-pollinated on the first day of opening. Alternatively, 4-6 days after the first opening of each flower, the corolla collapses to push the anthers into contact with the stigma (Levy, 1988). This mechanism, therefore, can promote selfing, particularly without previous pollination. Also, geitonogamy is possible as small pollinators can fly from one flower to another of the same plant (R. F. del Castillo, personal observation).

The use of male sterile plants may underestimate the rates of biparental inbreeding because, as was discussed above, floral morphology may enhance pollination distances. Also, these plants have a higher genetic load than hermaphrodites (del Castillo, 1992, 1993) favouring, therefore, a higher bias towards outcrossing (see Moran \& Brown, 1980; Cheliak et al., 1985; Snyder et al., 1985): Thus, genetical and morphological factors in male steriles might not only account for the lack of apparent inbreeding but also explain why the estimates of consanguineous matings using male sterile individuals were actually biased in favour of outcrossing. In any case, assortative mating appears not to be the main component of inbreeding in $P$. dubia.

Inbreeding depression has been detected experimentally in $P$. dubia, particularly at early stages (del Castillo, 1992). This factor, therefore, may contribute to curtail the loss of genetic variation due to the bottleneck effect (see Lesica \& Allendorf, 1992).

In conclusion, $P$. dubia has a relatively constant mixed mating system and population genetic structure. Because of the reduction in population size and the distribution of all the individuals in a single patch of the original population, bottlenecks, as those of 1989 , can potentially promote loss of genetic diversity. Nevertheless, the effective population size during the bottleneck persisted at a relatively high level presumably because of a density-dependent increase in gene flow. In addition, the bottleneck effect seems to be minimized by the seed bank in the soil. The seed bank buffers changes in population size, helps preserve genetic diversity, and maintains genetic spatial structure. 
Moreover, inbreeding depression and gene flow via pollen being much longer than that via seeds may help prevent the decrease of heterozygosity levels during the bottleneck. Restricted pollen and seed dispersal may explain the genetic structuring detected; however, population subdivision accounts for only a minor part of the total inbreeding of the population. In contrast, autogamy appears to be the main contributor to population level inbreeding. The view of Loveless \& Hamrick (1984) that the mating system is the main factor in organizing the genetic structure in populations seems to be valid in $P$. dubia.

\section{Acknowledgements}

I thank my advisor Janis Antonovics for his support during the course of this study. Frosty Levy introduced me to the Phacelias and showed me some aspects of their biology and laboratory techniques. Janis Antonovics, Donald Stone, Marcy Uyenoyama, Elizabeth Lacey and an anonymous reviewer provided useful comments on earlier versions of the manuscript. The author was supported by CONACyT and the Botany Department of Duke University.

\section{References}

ALLARD, R. W. 1975. The mating system and microevolution. Genetics, 79, 115-126.

AUGSPURGER, C. K. 1980. Mass-flowering of a tropical shrub (Hybanthus prunifolious): influence of pollinator attraction and movement. Evolution, 34, 475-488.

BAILEY, N. T. J. 1961. Introduction to the Theory of Genetic Linkage. Oxford University Press, London.

BASKIN, J. M. AND BASKIN, C. C. 1973. Delayed germination in seeds of Phacelia dubia var. dubia. Can. J. Bot., 51, 2481-2486

BASKIN, J. M. AND BASKIN, C. C. 1978. Role of temperature in the regulation of the life cycle of the winter annual Phacelia dubia var. dubia in the Tennessee Cedar Glades. J. Tenn. Acad. Sci., 53, 118-120.

BETANCOURT, J. L., SCHUSTER, W. S., MITTON, J. B. AND ANDERSON, R. s. 1991. Fossil and genetic history of a pinyon pine (Pinus edulis) isolate. Ecology, 72, 1685-1697.

BRown, A. H. D. 1979. Enzyme polymorphism in plant populations. Theor. Pop. Biol., 15, 1-42.

BURRows, F. M. 1986. The aerial motion of seeds, fruits, spores and pollen. In: Murray, D. R. (ed.) Seed Dispersal, pp. 2-47. Academic Press, Sydney.

CHAMBERS, J. C., MACMAHON, J. A. AND HAEFNER, J. H. 1991. Seed entrapment in alpine ecosystems: effects of soil particle size and diaspora morphology. Ecology, 72, 1668-1677.

CHARLESWORTH, D. 1991. The apparent selection on neutral marker loci in partially inbreeding populations. Gen. Res., 57, 159-175.

CHELIAK, W. M., DANCIK, B. P., MORGAN, K., YEH, F, C. H. AND STROBECK, C. 1985. Temporal variation of the mating system in a natural population of Jack Pine. Genetics, 109, 569-584.

ClEGG, M. T. 1980. Measuring plant mating systems: BioScience, 30, 814-818.

CleGG, M. T. AND Allard, R. w. 1972. Patterns of genetic differentiation in the slender wild oat species Avena barbata. Proc. Natl. Acad. Sci. U.S.A., 69, 1820-1824.

COCKERHAM, C. C. 1969. Variance in gene frequencies. Evolution, 23, 72-84.

CONOver, w. J. 1980. Practical Nonparametric Statistics. John Wiley, New York.

COOK, R. 1980. The biology of seeds in the soil. In: Solbrig, O. T. (ed.) Demography and Evolution in Plant Populations, pp. 107-129. Blackwell Scientific Publications, Oxford.

CROW, J. F. AND AOKI, K. 1984. Group selection for a polygenic behavioral trait: estimation of the degree of population subdivision. Proc. Natl. Acad. Sci. U.S.A., 81, 6073-6077.

CROW, J. F. AND KIMURA, M. 1970. An Introduction to Population Genetics Theory. Harper and Row, New York.

CUGEN, J., MERZEAUं, D. AND THIEBAUT, B. 1988. Genetic structure of the European beech stands (Fagus sylvatica L.): F-statistics and importance of mating systems characteristics in their evolution. Heredity, 60, 91-100.

DEL CASTILlO, R. F. 1992. Breeding system consequence in Phacelia dubia. Ph. D Thesis, Duke University.

DEL CASTILlO, R. F. 1993. Consequences of male sterility in Phacelia dubia. Evol. Tre. Pl., 7, 15-22.

DEWEY, S. E. AND HEYWOOD, J. S. 1988. Spatial genetic structure in a population of Psychotria nerviosa. I. Distribution of genotypes. Evolution, 42, 834-838.

ELLSTRAND, N. C. AND FOSTER, K. w. 1983. Impact of population structure on the apparent outcrossing rate of grain sorghum (Sorghum bicolor). Theor. Appl. Genet., 66, 323-327.

ENNOS, R. A. AND CLEGG, M. T. 1982. Effect of population substructuring on estimates of outcrossing rate in plant populations. Heredity, 48, 283-292.

EPLING, C., LEWIS, H. AND BALL, F. M. 1960. The breeding group and seed storage: a study in population dynamics. Evolution, 14, 238-255.

FENSTER, C. B. 1991. Gene flow in Chamaecrista fasciculata (Leguminosae). I. Gene dispersal. Evolution, 45 , 398-409.

FOWLER, D. P. AND MORRIS, R. W. 1977. Genetic diversity in red pine: evidence for low genetic heterozygosity. Can. J. For. Res., 7, 343-347.

FREEMAN, D. H. 1987. Applied Categorical Data Analyses. Mercel Dekker, New York.

FU, Y. B., KNOWLES, P. AND PERRY, D. J. 1992. Pollen pool heterogeneity in jack pine (Pinus banksiana Lamb.): a problem for estimating outcrossing rates. Theor. Appl. Genet., 83, 500-508.

GOTTLIEB, L. D. 1974. Genetic stability in a peripheral isolate of Stephanomeria exigua ssp. coronaria that fluctuates in population size. Genetics, 76, 551-556.

GOUYON, P. H., VICHOT, F. AND VAN DAMME, J. M. M. 1991. Nucleocytoplasmic male sterility: single point equilibria versus limit cycles. Am. Nat., 137, 498-515.

HALDANE, J. B. S. 1949. The association of characters as a result of inbreeding and linkage. Ann. Eugen., 15, 15-23. 
HANDEL, S. N. 1983a. Pollination ecology, plant population structure and gene flow. In: Real, L. E. (ed.) Pollination Biology, pp. 163-211. Academic Press, Orlando.

HANDEL, S. N. 1983b. Contrasting gene flow patterns and genetic subdivision in adjacent populations of Cucumis sativus (Cucurbitaceae). Evolution, 37, 760-771.

HEDRICK, P. w. 1980. Hitchhiking: a comparison of linkage and partial selfing. Genetics, 94, 791-808.

HEYWOOD, J. S. 1991. Spatial analysis of genetic variation in plant populations. Ann. Rev. Ecol. Syst., 22, 335-355.

KIMURA, M. AND WEISS, G. H. 1964. The stepping stone model of population structure and the decrease of genetic correlation with distance. Genetics, 49, 561-576.

LACY, R. C. 1987. Loss of genetic diversity from managed populations: interacting effects of drift, mutation, immigration, selection and population subdivision. Conserv. Biol., 1, 143-158.

LEE, T. D. 1984. Effects of seed number per fruit on seed dispersal in Cassia fasciculata. Bot. Gaz., 145, 136-139.

LESICA, P. AND ALLENDORF, F. w. 1992. Are small populations of plants worth preserving? Conserv. Biol., 6, 135-139.

LESICA, P., LEARY, R. F., ALLENDORF, F. W. AND BILDERBAK, D. E. 1988. Lack of genetic diversity within and among populations of an endangered plant, Howellia aquatilis. Conserv. Biol., 2, 275-282.

LEVIN, D. A. 1981. Dispersal versus gene flow in plants. Ann. Mo. Bot. Gard., 68, 233-253.

LEVIN, D. A. AND KERSTER, H. W. 1968. Local gene dispersal in Phlox. Evolution, 22, 130-139.

LEVIN, D. A. AND KERSTER, H. W. 1974. Gene flow in seed plants. Evol. Biol., 7, 139-220.

LEVY, F. 1988. Effects of pollen source and time of pollination on seed production and seed weight in Phacelia dubia and P. maculata (Hydrophyllaceae). Am. Midl. Nat., 119, 193-198.

LEVY, F. 1989. Mechanisms of speciation in Phacelia. Ph. D Thesis, Duke University.

LEVY, F. 1991. Morphological differentiation in Phacelia dubia and P. maculata. Rhodora, 93, 11-25.

LOVELESS, M. D. AND HAMRICK, J. L. 1984. Ecological determinants of genetic structure in plant populations. Ann. Rev. Ecol. Syst., 15, 65-95.

LOVELESS, M. D. AND HAMRICK, J. L. 1987. Distribución de la variación en especies de árboles tropicales. Rev. Biol. Trop., 35, 165-175.

MACARTHUR, R. H. AND WILSON, E. o. 1967. The Theory of Island Biogeography. Princeton University Press, Princeton, NJ.

MATHER, K. 1946. Statistical Analysis in Biology, 2nd edn. Interscience, New York.

MORAN, G. F. AND BROWN, A. H. D. 1980. Temporal heterogeneity of outcrossing rates in alpine ash (Eucalyptus delegatensis R. T. Bak). Theor. Appl. Genet., 57, 101-105.

MURCIA, C. 1990. Effect of floral morphology and temperature on pollen receipt and removal in Ipomoea trichocarpa. Ecology, 71, 1098-1109.

MURDY, w. H. 1966. The systematics of Phacelia maculata and $P$. dubia var. georgiana, both endemic to granite outcrop communities. Am. J. Bot., 53, 1028-1036.
NEI, M., MARUYAMA, T. AND CHAKRABORTY, R. 1975. The bottleneck effect and genetic variability in populations. Evolution, 29, 1-10.

OHTA, T. AND COCKERHAM, C. C. 1974. Detrimental genes with partial selfing and effects on a neutral locus. Genet. Res., 23, 191-200.

PRICE, M. V. AND WASER, N. M. 1982. Experimental studies of pollen carryover: hummingbirds and Ipomopsis aggregata. Oecologia, 54, 353-358.

PRoUT, т. 1981. A note on the island model with sex dependent migration. Theor. Appl. Genet., 59, 327-332.

PULLIAM, H. R. 1988. Sources, sinks and population regulation. Am. Nat., 132, 652-661.

PUtman, P. A. 1964. Speciation in Phacelia dubia. M. Sc. Thesis, Emory University.

RITLAND, K. 1984. The effective proportion of self-fertilization with consanguineous matings in inbred populations. Genetics, 106, 139-152.

RITLAND, K. AND JAIN, $\mathrm{S}$. 1981. A model for the estimation of outcrossing rate and gene frequencies using $n$ independent loci. Heredity, 47, 35-52.

SAS INSTITUTE. 1987. SAS/STAT Guide for Personal Computers, Version 6. SAS Institute, Cary, NC.

SCHAAL, B. A. 1975. Population structure and local differentiation in Lyatris cylindracea. Am. Nat., 109, 511-528.

SCHAAL, B. A. 1980. Measurement of gene flow in Lupinus texensis. Nature, 284, 450-451.

SCHAAL, B. A. AND SMITH, w. G. 1980. The apportionment of genetic variation within and among populations of Desmodium nudiflorum. Evolution, 34, 214-221.

SCHWAEGERLE, K. E., GARBUTT, K. AND BAZZAZ, F. A. 1986. Differentiation among nine populations of Phlox. I. Electrophoretic and quantitative variation. Evolution, 40, 506-517.

SELANDER, R. K. AND whitTam, T. S. 1983. Protein polymorphisms and the genetic structure of populations. In: Nei, M. and Koehn, R. K. (eds) Evolution of Genes and Proteins, pp. 89-114. Sinauer Associates, Sunderland, MA.

SHAW, D. V., KAHLER, A. L. AND ALLARD, R. w. 1981. A multilocus estimator of mating system parameters in plant populations. Proc. Natl. Acad. Sci. USA, 78, 1298-1302.

SLATKIN, M. 1977. Gene flow and genetic drift in species subject to frequent local extinctions. Theor. Pop. Biol., 12, 253-262.

SLATKIN, M. 1985. Gene flow in natural populations. Ann. Rev. Ecol. Syst., 16, 393-430.

SLATKIN, M. 1987. Gene flow and the geographic structure of natural populations. Science, 236, 787-792.

SNYDER, T. P., STEWART, D. A. AND STRICKLER, A. F. 1985. Temporal analysis of breeding structure in jack pine (Pinus banksiana Lamb.) Can. J. For. Res., 15, 1159-1166.

SOLTIS, D. E., HAUFER, C. H., DARROW, D. C. AND GASTONY, G. J. 1983. Starch gel electrophoresis of ferns: a compilation of grinding buffers, gel and electrode buffers and staining schedules. Am. Fern J., 73, 9-27.

SOLTIS, P. S. AND SOLTTS, D. E. 1988. Genetic variation and population structure in the fern Blechnum spicant (Blechna- 
ceae) from Western North America. Am. J. Bot., 75, 37-44.

SUN, M. AND GANDERS, F. R. 1988. Mixed mating systems in Hawaiian Bidens. Evolution, 42, 516-527.

TAGGART, J. B., MCNALLY, S. F. AND SHARP, P. M. 1990. Genetic variability and differentiation among founder populations of the pitcher plant (Sarracenia purpurea L.) in Ireland. Heredity, 64, 177-183.

TEMPLETON, A. S. AND LEVIN, D. A. 1979. Evolutionary consequences of seed pools. Am. Nat., 114, 232-249.

TRENBERTH, K. E., BRANSTATOR, G. W. AND ARKIN, P. A. 1988. Origins of the 1988 North American drought. Science, 242, 1640-1645.

TURNER, M. E., STEPHENS, J. C. AND ANDERSON, W. W. 1982. Homozygosity and patch structure in plant populations as a result of nearest-neighbour pollination. Proc. Natl. Acad. Sci. U.S.A., 79, 203-207.

WADDINGTON, K. D. 1983. Foraging behavior of pollinators. In: Real, L. (ed.) Pollination Biology, pp. 213-239. Academic Press, Orlando.

WASER, N. M. 1983. The adaptive nature of floral traits: ideas and evidence. In Real, L. (ed.) Pollination Biology, pp. 241-285. Academic Press, Orlando.

WATKINSON, A. R. 1978. The demography of a sand dune annual: Vulpia fasciculata. III. The dispersal of the seeds. $J$. Ecol., 66, 483-498.
WEIR, B. S. 1990. Genetic Data Analysis. Sinauer Associates, Sunderland, MA.

WEIR, B. S. AND COCKERHAM, C. C. 1984 . Estimating $F$-statistics for the analysis of population structure. Evolution, 38, 1358-1370.

WRIGHT, s. 1932. The roles of mutation, inbreeding, crossbreeding and selection in evolution. Proc. Sixth Int. Cong. Gen., 1, 356-366.

WRIGHT, s. 1946. Isolation by distance under diverse systems of mating. Genetics, 31, 39-59.

Wrigit, s. 1969. The Evolution and Genetics of Populations, vol. 2, The Theory of Gene Frequencies. University of Chicago Press, Chicago.

WriGHT, s. 1977. The Evolution and Genetics of Populations, vol. 3, Experimental Results and Evolutionary Deductions. University of Chicago Press, Chicago.

wright, s. 1978. Variability Within and Among Natural Populations, vol. 4, Experimental Results and Evolutionary Deductions. University of Chicago Press, Chicago.

WRight, s. 1988. Surface of selective values revisited. Am. Nat., 131, 115-123.

YOUNG, H. J. AND STANTON, M. L. 1990. Influences of floral variation on pollen removal and seed production in wild radish. Ecology, 71, 536-547. 